Original Article

\title{
Induced Abortion and Sub-Sequent Prevalence of Contraceptive Type
}

\author{
Rabia Sultana, Asifa Abdul Jabbar Khuwaja, Sana Mubarik Ali
}

\begin{abstract}
OBJECTIVE: To determine the frequency of type of contraceptive usage after counselling in women seeking post abortion care.

METHODOLOGY: A quasi experimental trial was conducted at Department of Gynaecology \& Obstetrics Unit-I, JPMC, Karachi from August 2014 to May 2015. A sample of 753 married women age between 18-40, who had presented for induced abortion were included in the study

RESULTS: The mean \pm SD age was $31.47 \pm 5.54$ years which ranged from 18-40 years. After counselling, $59.1 \%$ females were started using any method of contraception. Most common method was oral contraceptive pills $27.6 \%, 14.6 \%$ used condoms, $11.4 \%$ had intrauterine device while $2.9 \%$ used injectable contraceptives, $1.5 \%$ used sub dermal implant $\& 1.1 \%$ used tubal ligation.

CONCLUSION: The current study found that if females have adequate knowledge about different methods of contraception and their capability to control birth spacing. So females can adopt any methods instead of conceiving unwanted pregnancy and then to go for induced abortion.
\end{abstract}

KEYWORDS: Induced abortion, Post-abortion care, Contraceptives, Intrauterine Device, Oral contraceptive pills.

This article may be cited as: Sultana R, Khuwaja AAJ, Ali SM.Induced Abortion and Sub-Sequent Prevalence of Contraceptive Type. J Liaquat Uni Med Health Sci. 2019;18(02):104-8.

doi: 10.22442/jlumhs.191820610

\section{INTRODUCTION}

Every year out of 205 million pregnancies around 80 million unwanted pregnancies occur world-wide. Most of these occur due to non-use or inconsistent use of contraceptive methods. About one half of adolescent pregnant women between 15-19 yrs are unintended and one half of them end up in miscarriage ${ }^{1}$. Globally, each year about 22 million abortions are unsafe and occur in the developing countries $^{2}$. About 890,000 induced abortions occur every year in Pakistan, while the annual abortion rate is 29 per 1,000 women aged between $15-49$ years, it accounts for one abortion in every five live births. Young women seeking care in late gestation and goes to less skilled practitioner which leads to numerous complications ${ }^{3}$. It has been estimated that 80,000 maternal deaths per year take place because of abortion complications which accounts for $13 \%$ of maternal deaths in the world ${ }^{4}$.

Globally estimated contraceptive prevalence rate is $63.3 \%(60.4-66.0)$ or $8.5 \%$ points $(4.7-12.1$, PPI> $0.99)^{5}$. Pakistan was the first country among South Asian countries which recognized the importance of family planning services and introduced family planning programs in 1960 but it has got limited success in lowering the total fertility rate $^{3}$. Now contraception knowledge is almost widespread in Pakistan but the contraceptive prevalence rate is $35 \%$ from which $29 \%$ use modern methods while $9 \%$ use traditional methods ${ }^{6}$. Unmet need of contraception is $25 \%$ for last the 2 decades $^{7}$.

Contraceptive prevalence during post abortion care was found to be $72.9 \%$ in a study ${ }^{7}$. Amongst modern methods condoms and female sterilization are the most common methods being used, both $9 \%$. Other modern methods include injectable $3 \%$, Intrauterine Contraceptive Device (IUCD), pills and Lactational Amenorrhea Method (LAM) 2\% each. In traditional methods the use of withdrawal has increased more than two fold since 2006-07 (from $4 \%$ in 2006-07 to $9 \%$ in 2012-13). One important barrier for non-use of contraception is fear of side effects in women, particularly for methods requiring interventions such as IUD and tubal ligation ${ }^{7}$.

According to law in Pakistan abortion is only allowed on medical grounds to save the life of the woman or to provide necessary treatment. Despite of having adverse health effects of abortion women belonging to low socio-economic status still induces abortion as it has a one-time cost as compare to contraceptives. This entails that post-abortion counselling may be an effective tool 
to increase the usage of contraceptives. It encourages the uptake of contraceptives in the women and provides them emotional support so that they feel more secure and satisfied with the service ${ }^{8}$.

For many patients after abortion there is lack of family planning counselling and services which leads to another unplanned pregnancy after a short duration of time. The reason is that fertility returns within 2 to 3 weeks after abortion ${ }^{9}$. Current evidence recommends for healthy timing and spacing of pregnancy is at least 6 months ${ }^{10}$. Recent recommendation by $\mathrm{WHO}$ and scientific literature is provision of hormonal methods on day first of medical abortion ${ }^{11,12}$. Multiple studies have demonstrated the effectiveness of interferences to offer contraceptive counselling and methods to abortion customers earlier to discharge from health facilities

All this makes it essential to ensure that postabortion family planning counselling and delivery of contraceptive methods are offered to all women who present for post abortion care. The aim of this study was to determine the method of contraception adopted with proper counselling after induced abortion in females. It would help us to control population, and would help to improve maternal health as birth spacing provides time to improve maternal malnutrition, treat sepsis, it provides time to look after the children already present.

\section{METHODOLOGY}

A quasi experimental study was conducted at Department of Gynaecology \& Obstetrics Unit-I, JPMC, Karachi from August 2014 to May 2015. On basis of post abortion contraceptive prevalence found in previous studies which was $72.9 \%$ (modern methods condoms and female sterilization both $9 \%$, other modern methods include injectable $3 \%$, Intrauterine Contraceptive Device (IUCD), pills and Lactational Amenorrhea Method (LAM) 2\% each) confidence interval $95 \%$ and margin of error $1 \%$ by using least frequency (i.e. pills and LAM 2\%) and computer program open Epi version 2, the sample size required in this study was 753 patients. Patients were included through non-probability consecutive sampling. Females 18-40 years, underwent induced abortion. Informed consent was taken. Demographic details including name, age, parity, gestational age at presentation were asked, then patients were counselled about the different contraceptive methods, their pros and cons and success in averting pregnancy. They were also asked about their knowledge regarding contraceptive method. Data entry and analysis was done through SPSS version 16.

\section{RESULTS}

The mean age of females was $31.47 \pm 5.54$ years which ranged from 18-40 years. There were 212 $(28.2 \%)$ were primiparous and $541(71.8 \%)$ were multiparous. There were $223(29.6 \%)$ illiterate and $530(70.4 \%)$ literate. Out of 530 literate patients, 233 $(43.9 \%)$ had primary education, $216(40.8 \%)$ had secondary education, $56(10.6 \%)$ were graduate while $25(4.7 \%)$ had other educational courses. Out of 753 females, $465(61.8 \%)$ were working women while $288(38.2 \%)$ were house wives. About 248 $(32.9 \%)$ had $<20,000 /-$ income, $469(62.3 \%)$ had 20 $-40,000 /$ - income while $36(4.8 \%)$ had $>40,000 /-$ income (Table I).

After counselling, $445 \quad(59.1 \%)$ started using contraceptives after abortion (Figure I).

Out of 445 females using contraceptive, 208 (46.7\%) were using contraceptive pills, 110 (24.7\%) were using condoms, 22 (4.9\%) used injectable contraceptives, $86(19.3 \%)$ had intrauterine device, $11(2.5 \%)$ had subdermal implant \& $8(1.8 \%)$ had tubal ligation (Table II)

TABLE I: DEMOGRAPHICS OF PATIENTS $(n=753)$

\begin{tabular}{|l|r|}
\hline Age (years) & $31.47 \pm 5.54$ \\
\hline Parity & $212(28.2 \%)$ \\
\hline Primiparous & $541(71.8 \%)$ \\
\hline Multiparous & \\
\hline Education & $223(29.6 \%)$ \\
\hline Illiterate & $530(70.4 \%)$ \\
\hline Educated & $233(43.9 \%)$ \\
\hline Primary & $216(40.8 \%)$ \\
\hline Secondary & $56(10.6 \%)$ \\
\hline Graduate & $25(4.7 \%)$ \\
\hline Other educational course & $465(61.8 \%)$ \\
\hline Occupation & $288(38.2 \%)$ \\
\hline House wives & $248(32.9 \%)$ \\
\hline Economic status & $469(62.3 \%)$ \\
\hline$<20,000$ & $36(4.8 \%)$ \\
\hline $20,000-40,000$ &
\end{tabular}




\section{FIGURE I: FREQUENCY OF USING CONTRACEPTIVE AFTER SEEKING POST- ABORTION COUNSELLING}

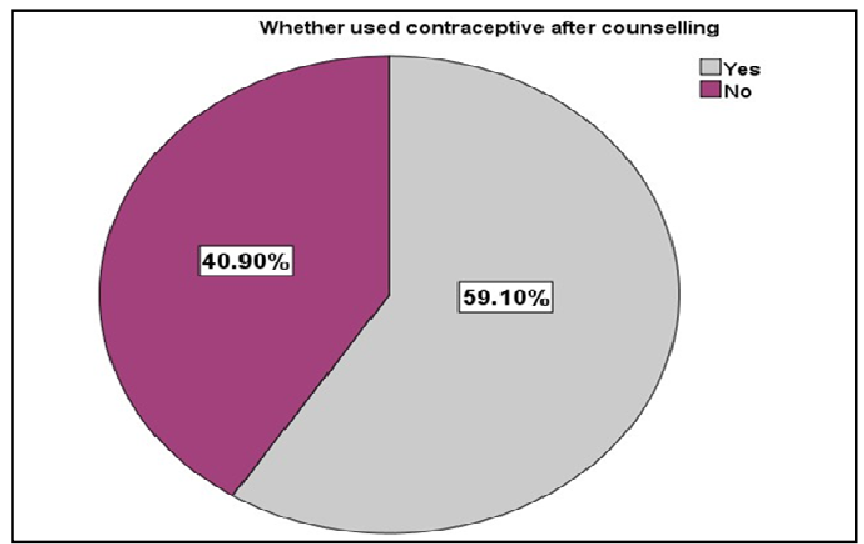

TABLE II: TYPE OF CONTRACEPTIVE USED BY PATIENTS AFTER SEEKING POST ABORTION COUNSELLING $(n=445)$

\begin{tabular}{|l|r|}
\hline \multicolumn{1}{|c|}{ Type of contraceptive } & \multicolumn{1}{c|}{ Frequency } \\
\hline Pills & $208(46.7 \%)$ \\
\hline Condoms & $110(24.7 \%)$ \\
\hline Injectable contraceptive & $22(4.9 \%)$ \\
\hline IUCD & $86(19.3 \%)$ \\
\hline Subdermal Implant & $11(2.5 \%)$ \\
\hline Tubal Ligation & $8(1.8 \%)$ \\
\hline
\end{tabular}

\section{DISCUSSION}

Contraception is an important aspect of reproductive health and plays a major role in the prevention of unwanted pregnancy. It is therefore a significant factor in reduction of induced. Advice about effective contraception following termination of pregnancy is essential to reduce termination of pregnancy rates.

The current study was conducted to assess the attitude of women towards choosing contraceptive methods after induced abortion. It was noted in the current study that $59.10 \%$ had chosen a method of contraceptive after seeking post abortion counselling. Zaidi S $2014^{13}$, found that only $9.2 \%$ women at $\mathrm{ASH}$, Karachi accepted contraceptive method. These numbers vary as $16.7 \%$ accepted contraceptive method pre-workshop at SPH, Quetta, which further increased upto $29.2 \%$ post-workshop. They also showed the rate of accepting contraceptive method after abortion was $25.8 \%$ at JPMC, Karachi. This rate was still lower in preceding years in the similar institute. When compared with international studies it was found that in a recent study from Nigeria ${ }^{14}$ that only $38 \%$ of the respondents desired to use contraceptives after abortion but only $10 \%$ did use one or other contraceptive method ${ }^{15}$.

Another study, taking a large national survey of women, the researcher evaluated the patterns of contraceptive use before and after an abortion. The study reported that $77 \%$ of women were used one or other method of contraception after abortion ${ }^{16}$. The study concluded that women who present for induced abortion are much highly like to accept one or other method of contraception and this timing offers an opportunity to improve contraceptive uptake ${ }^{17}$.

These rate differences among studies are due to regional differences and highlight the current situation of our population in comparison to less developed and developed nations. The current study also noted that choice of one or other method of contraception also varies with difference of region. The current study noted that oral contraceptive pills were highly preferred method and taken by $27.6 \%$ women, followed by condoms taken by $14.6 \%$, IUCD by $11.4 \%$ while injectable contraceptives, subdermal implant \& tubal ligation preference was least i.e. $2.9 \%, 1.5 \%$ \& $1.1 \%$ respectively. French study documented that post abortion, oral pill method was more frequency up taken (i.e. $27.3 \%$ ) followed by condoms and other barrier methods $(16.4 \%$ \& $18.3 \%$ ) while IUD was used by only $1.7 \%$ women $^{17}$. oral contraceptive pills were the most commonly selected method for each age group, followed by condoms and injectable. The least commonly chosen method was the IUD for women under 20 and implants for women in the other age groups ${ }^{18}$. The trend and rates of using contraceptives after abortion shown in this study mimic with the current study.

However the other studies describe dissimilar pattern of choice contraceptives. One study from Finland, reported that combined OCs were used by $49.5 \%$, contraceptive by $1.5 \%$ while intrauterine devices were taken up by $10 \%$ \& sterilization chosen by only $0.6 \%$ women after induced abortion. Likewise another study found that uptake rate of IUDs was $38.1 \%$, oral contraceptives $13.9 \%$ and $7.4 \%$ for tubal ligation among 8078 Turkish women $^{19}$. Thus we can say that there is great variation among choice of contraceptives taken up by the women after abortion. Further these choices may affected by other factors besides region. These factors may be age of woman, parity, socio-economic status, working status of women etc. The current study evaluated these factors. The mean $\pm S D$ age of women which had abortion was $31.47 \pm 5.54$ years which ranged from $18-40$ years. The current study noted that frequency of all types of contraceptives except oral pill was higher 
significantly among women elder ages. Compared to our results a study from Nigeria reported that mean age of the respondents was $23.5 \pm 4.4$ years and among this younger group of women uptake of temporary contraceptives was higher among younger age women while permanent methods like sterilization was more popular in elder age women ${ }^{15}$. Other studies reported that the mean age of women was 32.8 years which is a more than the mean age i.e. $23.5 \pm 4.4$ years of abortion seekers reported by current study ${ }^{20,21}$.

Further this study also found that $64 \%$ woman had secondary education and $33 \%$ possessed tertiary educational qualifications while others were illiterate $^{15}$. While in current study $31 \%$ studied up to primary, $40 \%$ up to secondary, $1.73 \%$ higher secondary, $1.46 \%$ graduates and about $26.16 \%$ were illiterate. In these patients use of subdermal implant, tubal ligation \& injectable contraceptives was more among highly educated women as compared to oral pills, condoms \& IUCD which were more common among less educated women. The previous study had taken a sample of all educated women therefore there was no analysis done regarding difference of contraceptive uptake between literate or illiterate women. Husband's level of education also did affect the use of contraception among these women significantly. Overall; the educated couples uptake contraception more than the non-educated couples.

The current study has highlighted a crucial area of women reproductive health. Many unwanted pregnancies can be prevented if effective contraceptive services will be provided to the women presenting for abortion. So, provision of family planning counselling and methods should be made a routine part of post abortion care in both public-and private sector facility ${ }^{22}$. Further there is a strong need to conduct further and wide spread research not only into the various factors that influence access to contraception but also factors that promote induced abortion.

\section{CONCLUSION}

The current study found that if females have adequate knowledge about different methods of contraception and their capability to control birth spacing. Out of all females, $59 \%$ were started using contraceptives to avoid unwanted pregnancy. So females can adopt any methods instead of conceiving unwanted pregnancy and then to go for induced abortion. The methods which methods can be safely used following medical abortion and can be initiated either on the day (oral pills, condoms and injectable contraceptives) or after the next menstrual cycle (intrauterine device and sterilization) are readily effective and well accepted by women.

Acknowledgment: We thank our colleagues at JPMC Karachi for their support in research work.

Ethical Permission: Ref. No. CPSP/REU/12901 dated: 06-01-2016.

Conflict of interest: There was no any conflict of interest.

Funding: There was no any funding agency.

\section{REFERENCES}

1. Dorroch JE, Woog V, Bankole A, Ashford L. Guttmatcher Institute [Internet]. Adding it Up: Costs and Benefits of Meeting the Contraceptive Needs of Adolescents. 2016; Available from: https://www.guttmacher.org/report/adding-itmeeting-contraceptive -needs-of-adolescents.

2. Ganatra B, Gerdts C, Rossier C, Johnson BR Jr, Tunçalp Ö, Assifi A, et al. Global, regional, and subregional classification of abortions by safety, 2010-14: estimates from a Bayesian hierarchical model. Lancet. 2017; 390(10110): 2372-81. doi: 10.1016/S0140-6736 (17)31794-4.

3. Mutua MM, Maina BW, Achia TO, Izugbara CO. Factors associated with delays in seeking post abortion care among women in Kenya. BMC Pregnancy Childbirth. 2015; 15(1): 241. doi: 10.1186/s12884-015-0660-7.

4. Ceylan A, Ertem M, Saka G, Akdeniz N. Post abortion family planning counseling as a tool to increase contraception use. BMC Public Health. 2009; 9: 20. doi:10.1186/1471-2458-9-20

5. Alkema L, Kantorova V, Menozzi C, Biddlecom A. National regional, and global rates and trends in contraceptive prevalence and unmet need for family planning between 1990 and 2015: A systematic and comprehensive analysis. Lancet. 2013; 381(9878): 1642-52. doi: 10.1016/S01406736(12)62204-1.

6. The Population Reference Bureau. The World's Youth 2013 Data Sheet. 2013; Available from: https://www.prb.org/youthdatasheet-2013/.

7. Bibi S, Soomro H, Ghaffar S, Pir MA. Met and unmet need of Family planning and associated factors in a remote rural area of Sindh, Pakistan. Pak J Med Sci. 2012; 28(3): 400-03.

8. Ferreira $A L$, Souza Al, Lima RA, Braga C. Choices on contraceptive methods in postabortion family planning clinic in the northeast Brazil. Reprod Health. 2010; 7: 5. doi: 10.1186/1742-4755-7-5

9. Curtis C, Huber D, Moss-Knight $\mathrm{T}$. Post-abortion Family planning: addressing the 
cycle of repeat unintended pregnancy and abortion. Int Perspect Sex Reprod Health. 2010; 36(1): 44-8. doi: 10.1363/ipsrh.36.044.10.

10. International Federation of Gynecology and Obstetrics; International Confederation of Midwives; International Council of Nurses; United States Agency for International Development; White Ribbon Alliance; Department for International Development, et al. Post abortion family planning: a key component of post abortion care. Washington, DC: 2013. Available from: https://www.glowm.com/pdf/PAC-FP-JointStatement-November2013-final_printquality.pdf

11. IPAS[Internet]. Clinical Updates in Reproductive Health. 2017. Available from: http://www.ipas. org/clinicalupdates.

12. WHO. Clinical Practice Handbook for Safe Abortion.[Internet] 2014. Available from: http://www.who.int/reproductivehealth/ publications/unsafe_abortion/clinical-practic e-safe-abortion/en/.

13. Zaidi S, Yasmin H, Hassan L, Khakwani M, Sami $\mathrm{S}$, Abbas T. Replacement of dilation and curettage/evacuation by manual vacuum aspiration and medical abortion, and the introduction of post abortion contraception in Pakistan. Int J Gynaecol Obstet. 2014;126 (Suppl 1): S40-S44. doi: 10.1016/j.ijgo.2014.03.016.

14. Adinma ED, Adinma JI, Eke NO, Iwuoha C, Akiode A, Oji E. Awareness and use of contraception by women seeking termination of pregnancy in south eastern Nigeria. Asian Pacific J Trop Dis. 2011; 1(1): 71-5. doi:10.1016/S22221808(11)60018-2

15. Marston C, Cleland J. Relationship between contraception and abortion: a review of the evidence. Int Fam Plan Perspect. 2003; 29(1): 6-13.

16. Moreau C, Trussell J, Desfreres J, Bajos N. Patterns of contraceptive use before and after an abortion: results from a nationally representative survey of women undergoing an abortion in France. Contraception. 2010; 82(4): 337-44. doi:10.1016/j.contraception.2010 .03.011.

17. Kjerulff $\mathrm{KH}$, Erickson BA, Langenberg PW. Chronic gynecological conditions reported by US women: finding from the National Health Interview Survey, 1984 to 1992. Am J Public Health. 1996; 86: 195-199.

18. Benson J, Andersen K, Healy J, Brahmia D. What Factors Contribute to Postabortion Contraceptive Uptake By Young Women? A Program Evaluation in 10 Countries in Asia and sub-Saharan Africa. Glob Health Sci Pract. 2017; 5(4): 644-57. doi: 10.9745/GHSP-D-17-00085.

19. Ozalp S, Yalcin OT, Hassa H, Erbay B, Dalan $\mathrm{N}$. Factors affecting the selection of a reversible or an irreversible contraceptive method in a developing country. Eur J Contracept Reprod Health Care. 2000; 5(2): 147-51.

20. Hern WM. Abortion Practice. Philadelphia: JB Lippincott; 1984.

21. Population council. Report on Unwanted pregnancy and post abortion complications in Pakistan: findings from a national Survey. Islamabad, Pakistan: Population Council; 2004.

22. Sathar Z, Singh S, Rashida G, Shah Z, Niazi R. Induced abortions and unintended pregnancies in Pakistan. Stud Fam Plan. 2014; 45(4): 471-91. doi: 10.1111/j.1728-4465.2014.00004.x.

\begin{tabular}{l} 
AUTHOR AFFILIATION: \\
Dr. Rabia Sultana \\
Senior Registrar \\
Department of Obstetrics \& Gynaecology \\
Gambat Institute of Medical Sciences \\
(GIMS), Khairpur Mirs, Sindh-Pakistan. \\
Dr. Asifa Abdul Jabbar Khuwaja (Corresponding Author) \\
Assistant Professor \\
Department of Obstetrics \& Gynaecology \\
(GIMS), Khairpur Mirs, Sindh-Pakistan. \\
Email: drasifakhawaja@yahoo.com \\
Dr. Sana Mubarik Ali \\
Senior Registrar \\
Department of Obstetrics \& Gynaecology \\
Civil Hospital Karachi, Sindh-Pakistan. \\
\hline
\end{tabular}

